\title{
Comparison of sequential estimation in response-adaptive designs with and without covariate-adjustment
}

\author{
Eunsik Park ${ }^{1, a}$ \\ ${ }^{a}$ Department of Statistics, Chonnam National University, Korea
}

\begin{abstract}
Subjects on one side of the covariate population can be allocated to the inferior treatment when there is interaction between the covariate and treatment along with a response-adaptive (RA) design without covariate adjustment. An RA design allows a newly entered subject to have a better chance so that the subject is treated by a superior treatment based on cumulative information from previous subjects. A covariate-adjusted responseadaptive (CARA) is the same as RA design and additionally adjusts the allocation based on individual covariate information. A comparison has been made for the sequential estimation procedure with and without covariate adjustment to see how ignoring significantly interactive covariate affects the correct treatment allocation. Using logistic models, we present simulation results regarding the coverage probability of treatment effect, correct allocation, and stopping time.
\end{abstract}

Keywords: covariate-adjustment, response-adaptive design, sequential estimation, stopping time

\section{Introduction}

In a response-adaptive (RA) design (Hu and Rosenberger, 2006; Zelen and Wei, 1995), the information collected from previously entered subjects is used and adjusts the allocation probability such that a newly entered subject can have a better chance for a superior treatment. The RA design serves ethical needs in performing clinical trials by allocating less numbers of subjects to inferior treatment. The sequential characteristic in this allocation process makes sequential statistical methods a natural choice for an RA design.

It is reasonable to additionally incorporate the available individual information of covariates that may affect responses if it is associated with treatments. We call this a covariate-adjusted responseadaptive (CARA) design. For example, the the RA design may assign subjects to the wrong treatment if an interaction exists between treatment and covariate.

A comparison has been made for the sequential estimation procedure with and without covariate adjustment to see how ignoring significantly interactive covariate affects the treatment allocation. The rest of this paper is organized as follows. Section 2 describes a sequential estimation procedure for treatment effect. Section 3 presents simulation studies and real examples applied to logistic models and Section 4 provides the conclusion.

\footnotetext{
${ }^{1}$ Department of Statistics, Chonnam National University, 77, Yongbong-ro, Buk-gu, Gwangju 61186, Korea.

E-mail: espark02@gmail.com
}

Published 31 July 2016 / journal homepage: http://csam.or.kr

(c) 2016 The Korean Statistical Society, and Korean International Statistical Society. All rights reserved. 


\section{Sequential estimation of treatment effect in CARA designs}

$\mathrm{Hu}$ and Rosenberger (2006) show that it is rare to find literature regarding applying stopping rules proposed for sequential estimation procedure based on CARA design despite the characteristics of CARA design that make it a natural sequential problem. Chang and Park (2013) proposed a sequential procedure described in this section to estimate the treatment effect under a CARA design. They estimated the treatment effects under a CARA design in a clinical trial such that the estimates satisfy a prescribed precision, while the number of subjects allocated to the superior treatment can be maximized without dimming the quality and efficiency to estimate treatment effects.

Suppose that $X_{1}, X_{2}, \ldots$ is the sequence of random treatment assignments, and $X_{m}=\left(X_{m, 1}, \ldots\right.$, $\left.X_{m, K}\right), X_{m, k} \in\{0,1\}$, denotes assignment of treatment $k$ to $m^{\text {th }}$ subject. Then $X_{m, k}=1$ for some $k$ and $\sum_{k=1}^{K} X_{m, k}=1$. That is, each subject is allocated to one treatment only. Let $N_{m, k}$ be the number of subjects assigned to treatment $k$ during the first $m$ assignments. Suppose that $\left\{Y_{m, k}, m=\right.$ $1,2, \ldots, k=1, \ldots, K\}$ denotes responses of $m^{\text {th }}$ subject to $k^{\text {th }}$ treatment. Let $\xi_{m}$ be covariates of $m^{\text {th }}$ subject. Assume the allocation function $\pi(\cdot, \cdot)=\left(\pi_{1}(\cdot, \cdot), \ldots, \pi_{K}(\cdot, \cdot)\right)$ with $\sum_{k=1}^{K} \pi_{k}=1$ and $0<v_{k}=$ $E_{\xi}\left[\pi_{k}(\theta, \xi)\right]<1, k=1, \ldots, K$. Assume further that for fixed $\xi, \pi_{k}(\theta, \xi)>0$ is a continuous function of $\theta$ and is differentiable with respect to $\theta$ such that $v_{k}(\tilde{\theta})=v_{k}(\theta)+(\tilde{\theta}-\theta)\left(\partial v_{k} / \partial \tilde{\theta}\right)^{\prime}+o\left(\|\tilde{\theta}-\theta\|^{1+\zeta}\right)$ for some $\zeta>0$, and let $v=\left(v_{1}, \ldots, v_{K}\right)$. Suppose that for each $m \geq 1$, the responses and covariates satisfy

$$
E\left[Y_{m, k} \mid \xi_{m}\right]=\mu_{k}\left(\theta_{k}, \xi_{m}\right),
$$

where $\mu_{k}(\cdot, \cdot), k=1, \ldots, K$, are known functions, and let $V=\operatorname{diag}\left\{V_{1}, \ldots, V_{K}\right\}$ where $V_{k}$ denotes the covariance matrix based on equation (2.1). Hence, it follows from equation (2.1) and $V$ that the method of generalized linear models can be applied according to McCullagh and Nelder (1989).

\subsection{The sequential procedure with the stopping rule}

The effective sample size for a clinical trial with adaptive design is usually unavailable. Hence, the sequential method, which allows the sample size to be determined based on the observed information, is therefore an adequate choice to make an efficient and valid statistical inference. A sequential method is also a natural choice in an RA design since the treatment allocation process itself is sequential, and its stopping rule is described in this section.

Assume that $\theta_{k} \in \Theta_{k} \subseteq R^{p}$ for $k=1, \ldots, K$, and let the parameter space $\Theta=\prod_{k=1}^{K} \Theta_{k}$. Under the above assumptions (also Condition A of Zhang et al. (2007), Theorem 2.1), asymptotic normality of $\hat{\theta}$ is proved that as $\min \left(N_{m, k}, k=1, \ldots, K\right)$ goes to infinity. $\hat{\theta}$ is the maximum quasi-likelihood estimate of $\theta$ based on previous observations. See Section A.1 of Chang and Park (2013) for details on the estimation procedure. The confidence set of $\theta=\left(\theta_{1}, \ldots, \theta_{K}\right)$ is therefore defined to be

$$
R_{\delta}=\left\{\theta \in \Theta: n(\hat{\theta}-\theta)^{\prime} V^{-1}(\hat{\theta}-\theta) \leq C_{\alpha}^{2}\right\},
$$

where $C_{\alpha}^{2}$ is the constant such that $P\left(\chi^{2}(p \cdot K) \geq C_{\alpha}^{2}\right) \leq \alpha . R_{\delta}$ denotes the confidence ellipsoid for given $\delta$. Suppose we require that the maximum axis of $R_{\delta}(\delta>0)$ be no larger than $2 \delta$ to control its size. The constant $\delta$ here is, therefore, used as a measure of precision of the confidence ellipsoid $R_{\delta}$. The minimum sample size to achieve this goal is

$$
n \Lambda_{\min }\left(V^{-1}\right) \geq \frac{C_{\alpha}^{2}}{\delta^{2}},
$$


where $\Lambda_{\min }(A)$ and $\Lambda_{\max }(A)$ are the minimum and maximum eigenvalues of matrix $A$. Thus the corresponding optimal sample size is

$$
n_{\text {opt }}=\text { first } n \text { such that } n \geq \frac{C_{\alpha}^{2} \Lambda_{\max }(V)}{\delta^{2}} .
$$

Once $V$ in equation (2.2) is estimated consistently by $\hat{V}$, a stopping rule for a fixed size confidence ellipsoid is suggested:

$$
\begin{aligned}
\tau_{\delta} & =\text { first } n \text { such that } n \geq \frac{C_{\alpha}^{2} \Lambda_{\max }(\hat{V})}{\delta^{2}} \\
& =\inf \left\{n \geq n_{0}: n \geq \frac{C_{\alpha}^{2} \Lambda_{\max }(\hat{V})}{\delta^{2}}\right\},
\end{aligned}
$$

where $n_{0} \geq K m_{0}$ is the minimum initial sample size and $m_{0}$ is the initial sample size for each treatment.

Chang and Park (2013) showed that $\hat{\theta}$ have the same asymptotic distribution if we replace the fixed sample size with a random sample size $\tau_{\delta}$ under the CARA design. They also showed that the same asymptotic property holds when we are interested in contrasts of parameters. For example, we are interested in estimating differences between treatment groups rather than estimating individual treatment effects.

\subsection{Treatment allocation}

In order to allocate more patients to the better treatment, Bandyopadhyay et al. (2007) suggests using the utility function below. They used this function under the CARA scheme for the two-stage design with binary responses.

Treatment allocation is implemented via the utility function, for $K$ treatments defined as

$$
U(p)=\log \left|\hat{I}_{n+1}\right|-\eta\left\{\sum_{k=1}^{K} p_{k} \log \left(\frac{p_{k}}{\pi_{k}(\hat{\theta}, \xi)}\right)\right\},
$$

where $\pi_{k}(\hat{\theta}, \xi)$ is the estimate of $\pi_{k}(\theta, \xi)$ denoting the estimate of the allocation probability for treatment $k$ up to the current stage $n$, and $\hat{I}_{n+1}$ is the estimate of Fisher information with a newly added subject and $n$ number of subjects up to the current stage. For a given covariate $\xi$ and the current estimate of $\theta$, the optimal allocation rule is to find the vector of allocation probabilities $p=\left(p_{1}, \ldots, p_{K}\right)$ that maximize the utility function above. That is, we allocate the $(n+1)^{\text {th }}$ subject to the treatment that maximizes the utility function; treatment allocation proportions are different so that the better treatment is allocated more often.

In the utility function, the first term depends on the information matrix. If $\eta=0$, then the new subject is selected to maximize the Fisher information matrix. However, if $\eta$ goes to $\infty$, then the optimal value of $p$ is to maximize the relative entropy function, the second term of equation (2.4). Hence, the parameter $\eta$ can be used to adjust the ethical and efficiency balance. Here we adopt the idea of a utility function to balance the needs for the estimation precision of treatment effects and the ethical consideration. Bandyopadhyay et al. (2007) showed some asymptotic properties of $p_{k} \mathrm{~s}$ theoretically along with some numerical results for various $\eta \mathrm{s}$. 
$\pi_{k}(\hat{\theta}, \xi)$, the second term in the utility function, can vary sequentially through $T_{n}$ at each allocation. For example, Chang and Park (2013) defined $\pi_{k}(\hat{\theta}, \xi)$ as follows with $K=2$ for illustration purposes.

$$
\pi_{1}(\hat{\theta}, \xi)=J\left(\frac{\xi^{\prime} \hat{\theta}_{1}-\xi^{\prime} \hat{\theta}_{2}}{T_{n}}\right) \quad \text { and } \quad \pi_{2}(\hat{\theta}, \xi)=1-\pi_{1}(\hat{\theta}, \xi)
$$

where $J(t)$ is to be positive non-trivial symmetric with respect to origin and integrable with respect to the distribution of $\xi$. Both $T_{n}$ and $\eta$ can serve as tuning parameters between efficiency and ethics and be random depending on the estimate's precision. $T_{n}$ can be a function of standard deviation of the treatment effect estimate based on cumulative observations up to $n^{\text {th }}$ subject. Please note that $T_{n}$ and $\eta$ are also tuned by a new covariate $\xi$ of the $(n+1)^{t h}$ subject.

By altering the parameters of the utility function in a utility function, at the beginning stage of a study, we can make more efforts to improve stability of treatment effects in terms of estimation precision. Once the estimate of treatment effects becomes stable as the sample size becomes large, we may assign more attention to the ethical part at the later stage of the study. We also tend to allocate more patients for the better treatment if there is sufficient information on treatment effects. The utility function facilitates the need for both the estimating treatment effects and the ethical consideration to be fulfilled and balanced accordingly.

\section{Numerical study}

The numerical study compares the performance of the estimate of the treatment effect and the allocation of subjects depending on whether the covariate interacting with treatment group is ignored in the treatment allocation process or not. In order to apply the sequential confidence estimation procedure, for $K$ treatments, and treatment allocation procedures in Section 2, for illustration purposes, we consider a binary response case in this study using the logistic model.

\subsection{Application to logistic models}

Suppose $Y_{k}=1(0)$ denotes a response variable with success (failure) from a subject assigned to treatment $k$ for $k=1, \ldots, K$. Let $\mu_{k}\left(\theta_{k}, \xi\right)=E\left[Y_{k}=1 \mid \xi\right]$, and $\theta_{k}=\left(\alpha_{k}, \theta_{k}^{*}\right)$. Assume that

$$
\operatorname{logit}\left(\mu_{k}\left(\theta_{k}, \xi\right)\right)=\alpha_{k}+\theta_{k}^{*} \xi, \quad k=1, \ldots, K .
$$

The covariate vector can be redefined as $(1, \xi)^{\prime}$, without loss of generality; therefore, we assume that $\alpha_{k}=0, k=1, \ldots, K$. Suppose there are $m_{0}$ initial samples for each treatment and assume that we are at the $m^{\text {th }}$ stage with $m>K m_{0}$.

We then compare the performance of the estimate of the treatment effect and the allocation of subjects of the two numerical studies to illustrate the importance of considering the covariate in the treatment allocation when it significantly interacts with the treatment groups.

\subsection{Simulation study}

The same parameter setup is made to compare our simulation results when the covariate is ignored as the one by Chang and Park (2013) when the covariate is considered in the treatment allocation.

We assume logistic models with binary responses, treatments $A$ and $B$ and one continuous covariate $X$. In the logistic models, we assume equal intercepts for both treatments $\left(\alpha_{A}, \alpha_{B}\right)=(0.1,0.1)$ and regression coefficients $\left(\beta_{A}, \beta_{B}\right)=(-1,1)$. The covariate is generated from a mixed normal distribution with means $2 \&-2$ and equal variance 1 with respective probability 0.5 (Figure 1 of Chang and 
Park (2013)). The treatment effect is defined as a function of differences of intercepts and regression coefficients between the two treatments; therefore, we apply the stopping rule for the contrasts of parameters, $\gamma=H^{\prime} \theta$. The transpose of the contrast $H$ is then defined as a matrix with its first row $(1,-1,0,0)$ and its second row $(0,0,1,-1)$, and the vector of parameters $\theta$ is $\left(\alpha_{A}, \alpha_{B}, \theta_{A}^{*}, \theta_{B}^{*}\right)^{\prime}$.

Precision $\delta$ is assumed 0.3 and initial sample size for each treatment, $m_{0}$, is assumed as 5,10 , and 15. Several combinations of tuning parameters $T_{n}$ and $\eta$ are assumed: $0.5,1$ and 2 for $T_{n}$ and $0,0.1$ and 1 for $\eta$. Both fixed and varying tuning parameters, $T_{n}$ and $\eta$, are considered; that is, $T_{n}$ and $\eta$ are fixed until the study stops, or vary whenever a new observation is added in a way that $T_{n}$ is proportional and $\eta$ is inversely proportional to the standard deviation of the treatment effect for a given covariate of a new observation. Findings from simulation studies are as follows (Table 1).

Here are findings from the numerical results when the covariate is ignored; stopping time is 30 if $2 m_{0}=30$, same as the total initial sample sizes, 28 if $2 m_{0}=20$ or if $2 m_{0}=10$ and $\eta=0.0$, and larger than 28 if $2 m_{0}=10$ and $\eta=0.1$ or 1.0 , i.e, stopping time is very early and similar unless initial sample size is very small with positive $\eta$. Varying $\eta$ or $T_{n}$ do not make differences in terms of stopping time. Stopping time is very stable unless initial sample size $m_{0}$ is small, such as 5 , where regression coefficient estimates are unstable at the beginning stage. The coverage probabilities of treatment differences cannot be computed because the covariate is ignored. Instead, coverages of intercept differences are given in Table 1 and are mostly larger than the nominal level 0.95 and become closer to 1 as the initial sample size $m_{0}$ gets larger, because there are less additional samples collected for larger $m_{0}$.

Correct allocation probabilities are mostly close to 0.5 , since the covariate is distributed symmetrically on both sides of intersection as in Figure 1 of Chang and Park (2013), in which varying $\eta$ or $T_{n}$ do not make any differences. This confirms that response-adaptive allocation ignoring significantly interacting covariate with treatment groups does not play an ethical role by failing to skew the allocation for better treatment group.

\subsection{Illustrative example}

It is not easy to find real data obtained from the CARA design; therefore, we present to illustrate a real example by modifying the study that applied non-response-adaptive design of Van Cutsem et al. (2009) into the CARA design but employing the same relationship between covariate, treatment group, and the response variable as one in this work. In this study, patients with epidermal growth factor receptor-positive colorectal cancer with unresectable metastases were randomly assigned to receive FOLFIRI either alone or in combination with cetuximab. They conducted a retrospective subgroup analysis to investigate the influence of the tumor KRAS mutation status on tumor response. There was a significant interaction between the treatment group and KRAS mutation status for tumor response when analyzed using the logistic regression model $(p=0.03)$. The adjusted odds ratio for a tumor response with cetuximab plus FOLFIRI treatment, as compared to FOLFIRI alone, was 1.40 (95\% CI, 1.12 to 1.77; $p=0.004$ ) (Figure 2B in Van Cutsem et al. (2009)). For each KRAS mutation status, number of tumor responses and the odds ratios along with their confidence intervals are given in Table 2 (Chang and Park, 2013).

This study was performed under the random treatment allocation; however, we simulate a situation as if it were done under the CARA design. We assume logistic models with binary tumor responses, two treatment groups and one binary covariate, KRAS status. In the logistic model, intercepts and regression coefficients are chosen so that the same odds ratios as in Van Cutsem et al. (2009) are achieved (Table 2)

The treatment effect is defined as a function of differences of intercepts and regression coefficients 
Table 1: Mean $(M)$ and standard deviation (SD) of stopping time $\left(\tau_{\delta_{\gamma}}\right)$, coverage probability $(\mathrm{CP})$ and correct allocation probability (CAP) of sequential 95\% confidence interval estimation with $\delta=0.3$ when the covariate interacting with treatment groups is ignored in the treatment allocation process

\begin{tabular}{|c|c|c|c|c|c|c|c|c|c|c|c|c|c|c|c|c|c|}
\hline \multirow[b]{2}{*}{$m_{0}$} & \multirow[b]{2}{*}{$T_{n}$} & \multirow[b]{2}{*}{$\eta$} & \multicolumn{2}{|c|}{ Variation } & \multicolumn{2}{|c|}{$\tau_{\delta_{\gamma}}$} & \multirow[b]{2}{*}{$\mathrm{CP}$} & \multirow[b]{2}{*}{ CAP } & \multirow[b]{2}{*}{$m_{0}$} & \multirow[b]{2}{*}{$T_{n}$} & \multirow[b]{2}{*}{$\eta$} & \multicolumn{2}{|c|}{ Variation } & \multicolumn{2}{|c|}{$\tau_{\delta_{\gamma}}$} & \multirow[b]{2}{*}{$\mathrm{CP}$} & \multirow[b]{2}{*}{ CAP } \\
\hline & & & $T_{n V}$ & $\eta_{V}$ & $M$ & SD & & & & & & $T_{n V}$ & $\overline{\eta_{V}}$ & $M$ & SD & & \\
\hline 5 & 0.5 & 0.0 & $\mathrm{~N}$ & $\mathrm{~N}$ & 28 & 1 & 1.00 & 0.50 & 10 & 1.0 & 0.1 & $\mathrm{Y}$ & $\mathrm{Y}$ & 28 & 2 & 0.99 & 0.50 \\
\hline 5 & 0.5 & 0.0 & $\mathrm{Y}$ & $\mathrm{N}$ & 28 & 1 & 1.00 & 0.50 & 10 & 1.0 & 1.0 & $\mathrm{~N}$ & $\mathrm{~N}$ & 28 & 4 & 0.99 & 0.50 \\
\hline 5 & 0.5 & 0.1 & $\mathrm{~N}$ & $\mathrm{~N}$ & 36 & 18 & 0.96 & 0.50 & 10 & 1.0 & 1.0 & $\mathrm{~N}$ & $\mathrm{Y}$ & 28 & 3 & 1.00 & 0.49 \\
\hline 5 & 0.5 & 0.1 & $\mathrm{~N}$ & $\mathrm{Y}$ & 38 & 21 & 0.93 & 0.50 & 10 & 1.0 & 1.0 & $\mathrm{Y}$ & $\mathrm{N}$ & 28 & 2 & 0.99 & 0.49 \\
\hline 5 & 0.5 & 0.1 & $\mathrm{Y}$ & $\mathrm{N}$ & 36 & 16 & 0.96 & 0.50 & 10 & 1.0 & 1.0 & $\mathrm{Y}$ & $\mathrm{Y}$ & 28 & 2 & 1.00 & 0.49 \\
\hline 5 & 0.5 & 0.1 & $\mathrm{Y}$ & $\mathrm{Y}$ & 35 & 15 & 0.97 & 0.50 & & & & & & & & & \\
\hline 5 & 0.5 & 1.0 & $\mathrm{~N}$ & $\mathrm{~N}$ & 39 & 20 & 0.94 & 0.50 & 10 & 2.0 & 0.0 & $\mathrm{~N}$ & $\mathrm{~N}$ & 28 & 1 & 1.00 & 0.51 \\
\hline 5 & 0.5 & 1.0 & $\mathrm{~N}$ & Y & 38 & 18 & 0.95 & 0.50 & 10 & 2.0 & 0.0 & $\mathrm{Y}$ & $\mathrm{N}$ & 28 & 1 & 1.00 & 0.49 \\
\hline 5 & 0.5 & 1.0 & $\mathrm{Y}$ & $\mathrm{N}$ & 39 & 19 & 0.95 & 0.50 & 10 & 2.0 & 0.1 & $\mathrm{~N}$ & $\mathrm{~N}$ & 28 & 1 & 1.00 & 0.49 \\
\hline \multirow[t]{2}{*}{5} & 0.5 & 1.0 & $\mathrm{Y}$ & $\mathrm{Y}$ & 38 & 18 & 0.95 & 0.50 & 10 & 2.0 & 0.1 & $\mathrm{~N}$ & $\mathrm{Y}$ & 28 & 1 & 1.00 & 0.50 \\
\hline & & & & & & & & & 10 & 2.0 & 0.1 & $\mathrm{Y}$ & $\mathrm{N}$ & 28 & 1 & 1.00 & 0.50 \\
\hline 5 & 1.0 & 0.0 & $\mathrm{~N}$ & $\mathrm{~N}$ & 28 & 1 & 1.00 & 0.50 & 10 & 2.0 & 0.1 & $\mathrm{Y}$ & $\mathrm{Y}$ & 28 & 2 & 1.00 & 0.49 \\
\hline 5 & 1.0 & 0.0 & $\mathrm{Y}$ & $\mathrm{N}$ & 28 & 1 & 1.00 & 0.50 & 10 & 2.0 & 1.0 & $\mathrm{~N}$ & $\mathrm{~N}$ & 28 & 1 & 1.00 & 0.50 \\
\hline 5 & 1.0 & 0.1 & $\mathrm{~N}$ & $\mathrm{~N}$ & 31 & 12 & 0.98 & 0.50 & 10 & 2.0 & 1.0 & $\mathrm{~N}$ & $\mathrm{Y}$ & 28 & 1 & 1.00 & 0.50 \\
\hline 5 & 1.0 & 0.1 & $\mathrm{~N}$ & $\mathrm{Y}$ & 31 & 10 & 0.98 & 0.50 & 10 & 2.0 & 1.0 & $\mathrm{Y}$ & $\mathrm{N}$ & 28 & 2 & 1.00 & 0.50 \\
\hline 5 & 1.0 & 0.1 & $\mathrm{Y}$ & $\mathrm{N}$ & 29 & 4 & 0.99 & 0.50 & 10 & 2.0 & 1.0 & $\mathrm{Y}$ & $\mathrm{Y}$ & 28 & 1 & 1.00 & 0.49 \\
\hline 5 & 1.0 & 0.1 & $\mathrm{Y}$ & $\mathrm{Y}$ & 30 & 5 & 0.99 & 0.51 & & & & & & & & & \\
\hline 5 & 1.0 & 1.0 & $\mathrm{~N}$ & $\mathrm{~N}$ & 33 & 16 & 0.96 & 0.50 & 15 & 0.5 & 0.0 & $\mathrm{~N}$ & $\mathrm{~N}$ & 30 & 0 & 1.00 & 0.54 \\
\hline 5 & 1.0 & 1.0 & $\mathrm{~N}$ & $\mathrm{Y}$ & 35 & 17 & 0.95 & 0.50 & 15 & 0.5 & 0.0 & Y & $\mathrm{N}$ & 30 & 0 & 1.00 & 0.55 \\
\hline 5 & 1.0 & 1.0 & $\mathrm{Y}$ & $\mathrm{N}$ & 31 & 7 & 0.99 & 0.50 & 15 & 0.5 & 0.1 & $\mathrm{~N}$ & $\mathrm{~N}$ & 30 & 0 & 1.00 & 0.38 \\
\hline 5 & 1.0 & 1.0 & $\mathrm{Y}$ & $\mathrm{Y}$ & 31 & 9 & 0.98 & 0.49 & 15 & 0.5 & 0.1 & $\mathrm{~N}$ & $\mathrm{Y}$ & 30 & 0 & 1.00 & 0.57 \\
\hline & & & & & & & & & 15 & 0.5 & 0.1 & $\mathrm{Y}$ & $\mathrm{N}$ & 30 & 1 & 1.00 & 0.53 \\
\hline 5 & 2.0 & 0.0 & $\mathrm{~N}$ & $\mathrm{~N}$ & 28 & 1 & 1.00 & 0.50 & 15 & 0.5 & 0.1 & $\mathrm{Y}$ & $\mathrm{Y}$ & 30 & 1 & 1.00 & 0.37 \\
\hline 5 & 2.0 & 0.0 & $\mathrm{Y}$ & $\mathrm{N}$ & 28 & 1 & 1.00 & 0.50 & 15 & 0.5 & 1.0 & $\mathrm{~N}$ & $\mathrm{~N}$ & 30 & 0 & 1.00 & 0.46 \\
\hline 5 & 2.0 & 0.1 & $\mathrm{~N}$ & $\mathrm{~N}$ & 28 & 3 & 0.99 & 0.50 & 15 & 0.5 & 1.0 & $\mathrm{~N}$ & $\mathrm{Y}$ & 30 & 0 & 1.00 & 0.64 \\
\hline 5 & 2.0 & 0.1 & $\mathrm{~N}$ & Y & 28 & 3 & 0.99 & 0.50 & 15 & 0.5 & 1.0 & $\mathrm{Y}$ & $\mathrm{N}$ & 30 & 0 & 1.00 & 0.52 \\
\hline 5 & 2.0 & 0.1 & $\mathrm{Y}$ & $\mathrm{N}$ & 28 & 1 & 1.00 & 0.50 & 15 & 0.5 & 1.0 & $\mathrm{Y}$ & $\mathrm{Y}$ & 30 & 0 & 1.00 & 0.39 \\
\hline 5 & 2.0 & 0.1 & $\mathrm{Y}$ & $\mathrm{Y}$ & 28 & 2 & 0.99 & 0.50 & & & & & & & & & \\
\hline 5 & 2.0 & 1.0 & $\mathrm{~N}$ & $\mathrm{~N}$ & 29 & 5 & 1.00 & 0.50 & 15 & 1.0 & 0.0 & $\mathrm{~N}$ & $\mathrm{~N}$ & 30 & 0 & 1.00 & 0.50 \\
\hline 5 & 2.0 & 1.0 & $\mathrm{~N}$ & $\mathrm{Y}$ & 29 & 6 & 0.99 & 0.49 & 15 & 1.0 & 0.0 & $\mathrm{Y}$ & $\mathrm{N}$ & 30 & 1 & 1.00 & 0.47 \\
\hline 5 & 2.0 & 1.0 & $\mathrm{Y}$ & $\mathrm{N}$ & 29 & 3 & 0.99 & 0.50 & 15 & 1.0 & 0.1 & $\mathrm{~N}$ & $\mathrm{~N}$ & 30 & 0 & 1.00 & 0.43 \\
\hline 5 & 2.0 & 1.0 & $\mathrm{Y}$ & $\mathrm{Y}$ & 29 & 3 & 0.99 & 0.50 & 15 & 1.0 & 0.1 & $\mathrm{~N}$ & $\mathrm{Y}$ & 30 & 2 & 1.00 & 0.31 \\
\hline & & & & & & & & & 15 & 1.0 & 0.1 & $\mathrm{Y}$ & $\mathrm{N}$ & 30 & 0 & 1.00 & 0.36 \\
\hline 10 & 0.5 & 0.0 & $\mathrm{~N}$ & $\mathrm{~N}$ & 28 & 1 & 1.00 & 0.50 & 15 & 1.0 & 0.1 & $\mathrm{Y}$ & $\mathrm{Y}$ & 30 & 0 & 1.00 & 0.38 \\
\hline 10 & 0.5 & 0.0 & $\mathrm{Y}$ & $\mathrm{N}$ & 28 & 1 & 1.00 & 0.48 & 15 & 1.0 & 1.0 & $\mathrm{~N}$ & $\mathrm{~N}$ & 30 & 1 & 1.00 & 0.42 \\
\hline 10 & 0.5 & 0.1 & $\mathrm{~N}$ & $\mathrm{~N}$ & 29 & 4 & 1.00 & 0.50 & 15 & 1.0 & 1.0 & $\mathrm{~N}$ & $\mathrm{Y}$ & 30 & 1 & 1.00 & 0.58 \\
\hline 10 & 0.5 & 0.1 & $\mathrm{~N}$ & $\mathrm{Y}$ & 29 & 3 & 0.99 & 0.49 & 15 & 1.0 & 1.0 & $\mathrm{Y}$ & $\mathrm{N}$ & 30 & 0 & 1.00 & 0.23 \\
\hline 10 & 0.5 & 0.1 & $\mathrm{Y}$ & $\mathrm{N}$ & 29 & 5 & 0.99 & 0.50 & 15 & 1.0 & 1.0 & $\mathrm{Y}$ & $\mathrm{Y}$ & 30 & 0 & 1.00 & 0.30 \\
\hline 10 & 0.5 & 0.1 & $\mathrm{Y}$ & $\mathrm{Y}$ & 29 & 4 & 0.99 & 0.49 & & & & & & & & & \\
\hline 10 & 0.5 & 1.0 & $\mathrm{~N}$ & $\mathrm{~N}$ & 29 & 4 & 0.99 & 0.49 & 15 & 2.0 & 0.0 & $\mathrm{~N}$ & $\mathrm{~N}$ & 30 & 0 & 1.00 & 0.56 \\
\hline 10 & 0.5 & 1.0 & $\mathrm{~N}$ & $\mathrm{Y}$ & 29 & 5 & 0.99 & 0.49 & 15 & 2.0 & 0.0 & $\mathrm{Y}$ & $\mathrm{N}$ & 30 & 0 & 1.00 & 0.48 \\
\hline 10 & 0.5 & 1.0 & $\mathrm{Y}$ & $\mathrm{N}$ & 29 & 3 & 0.99 & 0.51 & 15 & 2.0 & 0.1 & $\mathrm{~N}$ & $\mathrm{~N}$ & 30 & 0 & 1.00 & 0.32 \\
\hline 10 & 0.5 & 1.0 & $\mathrm{Y}$ & $\mathrm{Y}$ & 29 & 2 & 0.99 & 0.50 & 15 & 2.0 & 0.1 & $\mathrm{~N}$ & $\mathrm{Y}$ & 30 & 0 & 1.00 & 0.41 \\
\hline & & & & & & & & & 15 & 2.0 & 0.1 & $\mathrm{Y}$ & $\mathrm{N}$ & 30 & 0 & 1.00 & 0.56 \\
\hline 10 & 1.0 & 0.0 & $\mathrm{~N}$ & $\mathrm{~N}$ & 28 & 1 & 1.00 & 0.49 & 15 & 2.0 & 0.1 & $\mathrm{Y}$ & $\mathrm{Y}$ & 30 & 0 & 1.00 & 0.35 \\
\hline 10 & 1.0 & 0.0 & $\mathrm{Y}$ & $\mathrm{N}$ & 28 & 1 & 1.00 & 0.50 & 15 & 2.0 & 1.0 & $\mathrm{~N}$ & $\mathrm{~N}$ & 30 & 0 & 1.00 & 0.59 \\
\hline 10 & 1.0 & 0.1 & $\mathrm{~N}$ & $\mathrm{~N}$ & 28 & 3 & 0.99 & 0.50 & 15 & 2.0 & 1.0 & $\mathrm{~N}$ & $\mathrm{Y}$ & 30 & 0 & 1.00 & 0.35 \\
\hline 10 & 1.0 & 0.1 & $\mathrm{~N}$ & $\mathrm{Y}$ & 28 & 2 & 0.99 & 0.50 & 15 & 2.0 & 1.0 & $\mathrm{Y}$ & $\mathrm{N}$ & 30 & 0 & 1.00 & 0.29 \\
\hline 10 & 1.0 & 0.1 & $\mathrm{Y}$ & $\mathrm{N}$ & 28 & 2 & 0.99 & 0.50 & 15 & 2.0 & 1.0 & $\mathrm{Y}$ & $\mathrm{Y}$ & 30 & 0 & 1.00 & 0.66 \\
\hline
\end{tabular}

$T_{n V}$ and $\eta_{V}$ indicate whether $T_{n}$ and $\eta$ vary or not. 
Table 2: Tumor response summary to cetuximab plus FOLFIRI vs FOLFIRI alone treatment by KRAS status

\begin{tabular}{|c|c|c|c|c|c|}
\hline \multirow{2}{*}{ Tumor response } & \multicolumn{2}{|c|}{ Cetuximab plus FOLFIRI } & \multicolumn{2}{|c|}{ FOLFIRI alone } & \multirow{2}{*}{ Odds ratio } \\
\hline & Yes & No & Yes & No & \\
\hline KRAS population & 140 & 137 & 111 & 152 & $1.38(0.98-1.95)$ \\
\hline Mutant KRAS & 38 & 67 & 35 & 52 & $0.80(0.44-1.45)$ \\
\hline Wild-type KRAS & 102 & 70 & 76 & 100 & $1.91(1.24-2.93)$ \\
\hline
\end{tabular}

between the two treatments; therefore, we apply the stopping rule for the contrasts of parameters, $\gamma=H^{\prime} \theta$, given in Section 2.2 of Chang and Park (2013). Here, the transpose of the contrast $H$ is defined as a matrix with its first row $(1,-1,0,0)$ and its second row $(0,0,1,-1)$, and the vector of parameters $\theta$ is $\left(\alpha_{A}, \alpha_{B}, \theta_{A}^{*}, \theta_{B}^{*}\right)^{\prime}$.

Precision $\delta$ is assumed 0.2 and initial sample size for each treatment, $m_{0}$, is assumed as 15,20 , and 25. Several combinations of tuning parameters $T_{n}$ and $\eta$ are assumed: $0.1,0.3$ and 0.5 for $T_{n}$ and $0,0.01$ and 0.1 for $\eta$. Both fixed and varying tuning parameters, $T_{n}$ and $\eta$, are considered; that is, $T_{n}$ and $\eta$ are fixed until the study stops, or vary whenever a new observation is added in a way that $T_{n}$ is proportional and $\eta$ is inversely proportional to the standard deviation of the treatment effect for a given covariate of a new observation. Findings from simulation results when the KRAS status is considered are as follows (Table 3).

As $\eta$ gets larger, stopping time gets later but its increase is reduced as initial sample size gets larger. Varying $\eta$ or $T_{n}$ does not give significantly different results compared to fixed values. Stopping time is later and more unstable as $\eta$ is larger or initial sample size $m_{0}$ is smaller, due to unstable regression coefficient estimates at the beginning stage. The coverage probabilities of treatment differences becomes closer to 0.95 as the initial sample size $m_{0}$ gets larger and $\eta$ gets smaller.

For wild-type KRAS population, as $\eta$ gets larger, if $T_{n}=0.3$ and 0.5 , correct treatment allocation gets better with similar performance for positive $\eta$. This confirms that $\eta$ plays a role as a tuning parameter for ethical consideration and a small, nonzero $\eta$ is sufficient for correct allocation. However, if $T_{n}=0.1$, correct treatment allocation gets worse for positive $\eta$ and when $T_{n}$ is varying. $T_{n}=0.1$ is too small to secure accurate treatment estimate and subsequently inflate small treatment effect in the utility function to make wrong treatment allocation. For small $T_{n}$, non-increasing sensitivities are due to giving too much weight to ethical side by increasing $\eta$ before getting accurate estimates of treatment effect. This implies that we do not need to sacrifice accuracy by increasing $\eta$. Small positive $\eta$ is adequate to provide the ethical emphasis. CAP also greatly decreases when $T_{n}$ is 0.1 and variable due to smaller $T_{n}$ than 0.1 for varying $T_{n}$.

For mutant KRAS population, correct allocation is better when $\eta=0.01$ compared to $\eta=0.00$. However it is mostly not increased when $\eta$ is increased from 0.01 to 0.1 . This is also due to too much weight to the ethical side assigning large $\eta$ before estimating accurate treatment effect. Treatment allocation is best if $T_{n}=0.1$ for mutant KRAS because of easy detection of small treatment differences (odds ratio is small, 0.80, for mutant KRAS while it is large, 1.91, for wild-type KRAS). If we have to use the same $T_{n}$ for both KRAS status, then $T_{n}=0.3$ or 0.5 are recommended because differences of correct allocation are larger when $T_{n}=0.3$ or 0.5 compared to $T_{n}=0.1$ for each KRAS status. In summary, small positive $\eta$ is adequate for ethical consideration and reasonable sized $T_{n}$ is recommended for correct allocation because too small $T_{n}$ may yield decreasing correct allocation from 0.5 as $\eta$ is increased. Varying $\eta$ does not affect the correct allocation seriously but varying too small $T_{n}$ may decrease correct allocation greatly to smaller than 0.5 .

Findings from the numerical results when KRAS status is ignored are as follows (Table 4). Stopping time is 50 if $2 m_{0}=50$, same as the total initial sample sizes, mostly 40 if $2 m_{0}=40$ or if $2 m_{0}=30$, i.e, stopping time is very early and similar. Varying $\eta$ or $T_{n}$ do not make differences in 
Table 3: Mean $(M)$ and standard deviation (SD) of stopping time $\left(\tau_{\delta_{y}}\right)$, coverage probability $(\mathrm{CP})$ and correct allocation probabilities (CAP) of sequential 95\% confidence interval estimation with $\delta=0.2$ when the covariate interacting with treatment groups is considered in the treatment allocation process

\begin{tabular}{|c|c|c|c|c|c|c|c|c|c|c|c|c|c|c|c|c|c|c|c|}
\hline \multirow[b]{2}{*}{$m_{0}$} & \multirow[b]{2}{*}{$T_{n}$} & \multirow[b]{2}{*}{$\eta$} & \multicolumn{2}{|c|}{ Variation } & \multicolumn{2}{|c|}{$\tau_{\delta_{\gamma}}$} & \multirow[b]{2}{*}{$\mathrm{CP}$} & \multirow[b]{2}{*}{$\mathrm{CAP}_{w}$} & \multirow[b]{2}{*}{$\mathrm{CAP}_{m}$} & \multirow[b]{2}{*}{$m_{0}$} & \multirow[b]{2}{*}{$T_{n}$} & \multirow[b]{2}{*}{$\eta$} & \multicolumn{2}{|c|}{ Variation } & \multicolumn{2}{|c|}{$\tau_{\delta_{\gamma}}$} & \multirow[b]{2}{*}{$\mathrm{CP}$} & & \\
\hline & & & $T_{n V}$ & $\eta_{V}$ & $M$ & SD & & & & & & & $T_{n V}$ & $\eta_{V}$ & $M$ & SD & & $\mathrm{CAP}_{w}$ & $\mathrm{CAP}_{m}$ \\
\hline 15 & 0.1 & 0.00 & $\mathrm{~N}$ & $\mathrm{~N}$ & 131 & 6 & 0.98 & 0.51 & 0.52 & 20 & 0.3 & 0.01 & $\mathrm{Y}$ & $\mathrm{Y}$ & 169 & 41 & 0.90 & 0.81 & 0.61 \\
\hline 15 & 0.1 & 0.00 & $\mathrm{Y}$ & $\mathrm{N}$ & 132 & 11 & 0.97 & 0.51 & 0.52 & 20 & 0.3 & 0.10 & $\mathrm{~N}$ & $\mathrm{~N}$ & 173 & 36 & 0.88 & 0.86 & 0.63 \\
\hline 15 & 0.1 & 0.01 & $\mathrm{~N}$ & $\mathrm{~N}$ & 199 & 63 & 0.87 & 0.45 & 0.73 & 20 & 0.3 & 0.10 & $\mathrm{~N}$ & $\mathrm{Y}$ & 184 & 55 & 0.92 & 0.83 & 0.55 \\
\hline 15 & 0.1 & 0.01 & $\mathrm{~N}$ & $\mathrm{Y}$ & 199 & 75 & 0.86 & 0.44 & 0.70 & 20 & 0.3 & 0.10 & $\mathrm{Y}$ & $\mathrm{N}$ & 183 & 42 & 0.90 & 0.84 & 0.60 \\
\hline 15 & 0.1 & 0.01 & $\mathrm{Y}$ & $\mathrm{N}$ & 204 & 81 & 0.83 & 0.24 & 0.71 & 20 & 0.3 & 0.10 & $\mathrm{Y}$ & $\mathrm{Y}$ & 186 & 41 & 0.88 & 0.88 & 0.54 \\
\hline 15 & 0.1 & 0.01 & $\mathrm{Y}$ & $\mathrm{Y}$ & 210 & 72 & 0.83 & 0.23 & 0.74 & & & & & & & & & & \\
\hline 15 & 0.1 & 0.10 & $\mathrm{~N}$ & $\mathrm{~N}$ & 228 & 96 & 0.85 & 0.45 & 0.76 & 20 & 0.5 & 0.00 & $\mathrm{~N}$ & $\mathrm{~N}$ & 131 & 8 & 0.96 & 0.50 & 0.53 \\
\hline 15 & 0.1 & 0.10 & $\mathrm{~N}$ & $\mathrm{Y}$ & 219 & 90 & 0.88 & 0.45 & 0.73 & 20 & 0.5 & 0.00 & $\mathrm{Y}$ & $\mathrm{N}$ & 131 & 6 & 0.99 & 0.50 & 0.54 \\
\hline 15 & 0.1 & 0.10 & $\mathrm{Y}$ & $\mathrm{N}$ & 227 & 95 & 0.83 & 0.20 & 0.70 & 20 & 0.5 & 0.01 & $\mathrm{~N}$ & $\mathrm{~N}$ & 142 & 20 & 0.91 & 0.69 & 0.60 \\
\hline 15 & 0.1 & 0.10 & $\mathrm{Y}$ & $\mathrm{Y}$ & 211 & 78 & 0.86 & 0.20 & 0.72 & 20 & 0.5 & 0.01 & $\mathrm{~N}$ & $\mathrm{Y}$ & 144 & 23 & 0.92 & 0.74 & 0.55 \\
\hline & & & & & & & & & & 20 & 0.5 & 0.01 & $\mathrm{Y}$ & $\mathrm{N}$ & 150 & 26 & 0.92 & 0.81 & 0.60 \\
\hline 15 & 0.3 & 0.00 & $\mathrm{~N}$ & $\mathrm{~N}$ & 130 & 7 & 0.98 & 0.51 & 0.53 & 20 & 0.5 & 0.01 & $\mathrm{Y}$ & $\mathrm{Y}$ & 151 & 25 & 0.94 & 0.82 & 0.59 \\
\hline 15 & 0.3 & 0.00 & $\mathrm{Y}$ & $\mathrm{N}$ & 131 & 9 & 0.97 & 0.51 & 0.53 & 20 & 0.5 & 0.10 & $\mathrm{~N}$ & $\mathrm{~N}$ & 165 & 41 & 0.86 & 0.83 & 0.53 \\
\hline 15 & 0.3 & 0.01 & $\mathrm{~N}$ & $\mathrm{~N}$ & 156 & 36 & 0.90 & 0.77 & 0.57 & 20 & 0.5 & 0.10 & $\mathrm{~N}$ & $\mathrm{Y}$ & 161 & 42 & 0.93 & 0.82 & 0.58 \\
\hline 15 & 0.3 & 0.01 & $\mathrm{~N}$ & $\mathrm{Y}$ & 167 & 62 & 0.86 & 0.78 & 0.55 & 20 & 0.5 & 0.10 & $\mathrm{Y}$ & $\mathrm{N}$ & 162 & 30 & 0.92 & 0.82 & 0.60 \\
\hline 15 & 0.3 & 0.01 & $\mathrm{Y}$ & $\mathrm{N}$ & 172 & 42 & 0.87 & 0.84 & 0.58 & 20 & 0.5 & 0.10 & $\mathrm{Y}$ & $\mathrm{Y}$ & 174 & 41 & 0.87 & 0.82 & 0.51 \\
\hline 15 & 0.3 & 0.01 & $\mathrm{Y}$ & $\mathrm{Y}$ & 183 & 51 & 0.80 & 0.80 & 0.65 & & & & & & & & & & \\
\hline 15 & 0.3 & 0.10 & $\mathrm{~N}$ & $\mathrm{~N}$ & 197 & 58 & 0.84 & 0.85 & 0.58 & 25 & 0.1 & 0.00 & $\mathrm{~N}$ & $\mathrm{~N}$ & 131 & 7 & 0.97 & 0.50 & 0.55 \\
\hline 15 & 0.3 & 0.10 & $\mathrm{~N}$ & $\mathrm{Y}$ & 206 & 61 & 0.82 & 0.81 & 0.57 & 25 & 0.1 & 0.00 & $\mathrm{Y}$ & $\mathrm{N}$ & 131 & 7 & 0.99 & 0.50 & 0.55 \\
\hline 15 & 0.3 & 0.10 & $\mathrm{Y}$ & $\mathrm{N}$ & 198 & 71 & 0.90 & 0.83 & 0.59 & 25 & 0.1 & 0.01 & $\mathrm{~N}$ & $\mathrm{~N}$ & 152 & 18 & 0.98 & 0.53 & 0.62 \\
\hline 15 & 0.3 & 0.10 & $\mathrm{Y}$ & $\mathrm{Y}$ & 210 & 83 & 0.82 & 0.82 & 0.61 & 25 & 0.1 & 0.01 & $\mathrm{~N}$ & $\mathrm{Y}$ & 162 & 27 & 0.93 & & 0.69 \\
\hline & & & & & & & & & & 25 & 0.1 & 0.01 & $\mathrm{Y}$ & $\mathrm{N}$ & 157 & 22 & 0.96 & 0.28 & 0.72 \\
\hline 15 & 0.5 & 0.00 & $\mathrm{~N}$ & $\mathrm{~N}$ & 131 & 8 & 0.99 & 0.51 & 0.53 & 25 & 0.1 & 0.01 & $\mathrm{Y}$ & $\mathrm{Y}$ & 159 & 24 & 0.98 & 0.28 & 0.75 \\
\hline 15 & 0.5 & 0.00 & $\mathrm{Y}$ & $\mathrm{N}$ & 130 & 7 & 1.00 & 0.51 & 0.52 & 25 & 0.1 & 0.10 & $\mathrm{~N}$ & $\mathrm{~N}$ & 164 & 25 & 0.94 & 0.48 & 0.68 \\
\hline 15 & 0.5 & 0.01 & $\mathrm{~N}$ & $\mathrm{~N}$ & 146 & 34 & 0.93 & 0.70 & 0.53 & 25 & 0.1 & 0.10 & $\mathrm{~N}$ & $\mathrm{Y}$ & 163 & 23 & 0.97 & 0.52 & 0.63 \\
\hline 15 & 0.5 & 0.01 & $\mathrm{~N}$ & $\mathrm{Y}$ & 154 & 37 & 0.86 & 0.72 & 0.58 & 25 & 0.1 & 0.10 & $\mathrm{Y}$ & $\mathrm{N}$ & 162 & 24 & 0.94 & 0.23 & 0.65 \\
\hline 15 & 0.5 & 0.01 & $\mathrm{Y}$ & $\mathrm{N}$ & 160 & 41 & 0.86 & 0.79 & 0.58 & 25 & 0.1 & 0.10 & $\mathrm{Y}$ & $\mathrm{Y}$ & 163 & 28 & 0.98 & 0.28 & 0.75 \\
\hline 15 & 0.5 & 0.01 & $\mathrm{Y}$ & $\mathrm{Y}$ & 164 & 41 & 0.81 & 0.79 & 0.58 & & & & & & & & & & \\
\hline 15 & 0.5 & 0.10 & $\mathrm{~N}$ & $\mathrm{~N}$ & 166 & 40 & 0.90 & 0.79 & 0.55 & 25 & 0.3 & 0.00 & $\mathrm{~N}$ & $\mathrm{~N}$ & 132 & 7 & 0.98 & 0.50 & 0.54 \\
\hline 15 & 0.5 & 0.10 & $\mathrm{~N}$ & $\mathrm{Y}$ & 180 & 47 & 0.84 & 0.78 & 0.54 & 25 & 0.3 & 0.00 & $\mathrm{Y}$ & $\mathrm{N}$ & 131 & 6 & 0.99 & 0.50 & 0.55 \\
\hline 15 & 0.5 & 0.10 & $\mathrm{Y}$ & $\mathrm{N}$ & 174 & 40 & 0.91 & 0.83 & 0.54 & 25 & 0.3 & 0.01 & $\mathrm{~N}$ & $\mathrm{~N}$ & 145 & 18 & 0.92 & 0.79 & 0.56 \\
\hline 15 & 0.5 & 0.10 & $\mathrm{Y}$ & $\mathrm{Y}$ & 181 & 46 & 0.89 & 0.86 & 0.55 & 25 & 0.3 & 0.01 & $\mathrm{~N}$ & $\mathrm{Y}$ & 152 & 31 & 0.94 & 0.84 & 0.61 \\
\hline & & & & & & & & & & 25 & 0.3 & 0.01 & $\mathrm{Y}$ & $\mathrm{N}$ & 150 & 19 & 0.99 & 0.78 & 0.62 \\
\hline 20 & 0.1 & 0.00 & $\mathrm{~N}$ & $\mathrm{~N}$ & 131 & 8 & 0.98 & 0.50 & 0.54 & 25 & 0.3 & 0.01 & $\mathrm{Y}$ & $\mathrm{Y}$ & 156 & 23 & 0.94 & 0.83 & 0.59 \\
\hline 20 & 0.1 & 0.00 & $\mathrm{Y}$ & $\mathrm{N}$ & 132 & 8 & 0.96 & 0.50 & 0.55 & 25 & 0.3 & 0.10 & $\mathrm{~N}$ & $\mathrm{~N}$ & 163 & 30 & 0.96 & 0.86 & 0.57 \\
\hline 20 & 0.1 & 0.01 & $\mathrm{~N}$ & $\mathrm{~N}$ & 174 & 35 & 0.90 & 0.47 & 0.77 & 25 & 0.3 & 0.10 & $\mathrm{~N}$ & $\mathrm{Y}$ & 164 & 33 & 0.95 & 0.85 & 0.54 \\
\hline 20 & 0.1 & 0.01 & $\mathrm{~N}$ & $\mathrm{Y}$ & 173 & 40 & 0.92 & 0.54 & 0.71 & 25 & 0.3 & 0.10 & $\mathrm{Y}$ & $\mathrm{N}$ & 167 & 27 & 0.94 & 0.85 & 0.54 \\
\hline 20 & 0.1 & 0.01 & $\mathrm{Y}$ & $\mathrm{N}$ & 174 & 36 & 0.93 & 0.23 & 0.65 & 25 & 0.3 & 0.10 & $\mathrm{Y}$ & $\mathrm{Y}$ & 161 & 26 & 0.95 & 0.80 & 0.61 \\
\hline 20 & 0.1 & 0.01 & $\mathrm{Y}$ & $\mathrm{Y}$ & 175 & 42 & 0.91 & 0.24 & 0.70 & & & & & & & & & & \\
\hline 20 & 0.1 & 0.10 & $\mathrm{~N}$ & $\mathrm{~N}$ & 177 & 40 & 0.95 & 0.51 & 0.65 & 25 & 0.5 & 0.00 & $\mathrm{~N}$ & $\mathrm{~N}$ & 131 & 8 & 0.96 & 0.49 & 0.53 \\
\hline 20 & 0.1 & 0.10 & $\mathrm{~N}$ & $\mathrm{Y}$ & 181 & 45 & 0.93 & 0.51 & 0.69 & 25 & 0.5 & 0.00 & $\mathrm{Y}$ & $\mathrm{N}$ & 131 & 6 & 0.97 & 0.50 & 0.54 \\
\hline 20 & 0.1 & 0.10 & $\mathrm{Y}$ & $\mathrm{N}$ & 184 & 45 & 0.93 & 0.25 & 0.69 & 25 & 0.5 & 0.01 & $\mathrm{~N}$ & $\mathrm{~N}$ & 137 & 14 & 0.95 & 0.71 & 0.55 \\
\hline 20 & 0.1 & 0.10 & $\mathrm{Y}$ & $\mathrm{Y}$ & 182 & 34 & 0.90 & 0.30 & 0.78 & 25 & 0.5 & 0.01 & $\mathrm{~N}$ & $\mathrm{Y}$ & 139 & 13 & 0.94 & 0.74 & 0.58 \\
\hline & & & & & & & & & & 25 & 0.5 & 0.01 & $\mathrm{Y}$ & $\mathrm{N}$ & 139 & 12 & 0.98 & 0.76 & 0.59 \\
\hline 20 & 0.3 & 0.00 & $\mathrm{~N}$ & $\mathrm{~N}$ & 134 & 11 & 0.96 & 0.50 & 0.52 & 25 & 0.5 & 0.01 & $\mathrm{Y}$ & $\mathrm{Y}$ & 145 & 22 & 0.94 & 0.84 & 0.56 \\
\hline 20 & 0.3 & 0.00 & $\mathrm{Y}$ & $\mathrm{N}$ & 132 & 9 & 0.95 & 0.49 & 0.52 & 25 & 0.5 & 0.10 & $\mathrm{~N}$ & $\mathrm{~N}$ & 152 & 29 & 0.92 & 0.81 & 0.57 \\
\hline 20 & 0.3 & 0.01 & $\mathrm{~N}$ & $\mathrm{~N}$ & 158 & 44 & 0.90 & 0.77 & 0.53 & 25 & 0.5 & 0.10 & $\mathrm{~N}$ & $\mathrm{Y}$ & 153 & 26 & 0.96 & 0.84 & 0.61 \\
\hline 20 & 0.3 & 0.01 & $\mathrm{~N}$ & $\mathrm{Y}$ & 159 & 27 & 0.93 & 0.83 & 0.59 & 25 & 0.5 & 0.10 & $\mathrm{Y}$ & $\mathrm{N}$ & 155 & 23 & 0.89 & 0.85 & 0.54 \\
\hline 20 & 0.3 & 0.01 & $\mathrm{Y}$ & $\mathrm{N}$ & 162 & 29 & 0.94 & 0.82 & 0.59 & 25 & 0.5 & 0.10 & $\mathrm{Y}$ & $\mathrm{Y}$ & 157 & 24 & 0.91 & 0.88 & 0.60 \\
\hline
\end{tabular}

$T_{n V}$ and $\eta_{V}$ indicate whether $T_{n}$ and $\eta$ vary or not. 
Table 4: Mean $(M)$ and standard deviation (SD) of stopping time $\left(\tau_{\delta_{y}}\right)$, coverage probability $(\mathrm{CP})$ and correct allocation probabilities (CAP) of sequential 95\% confidence interval estimation with $\delta=0.2$ when the covariate interacting with treatment groups is ignored in the treatment allocation process

\begin{tabular}{|c|c|c|c|c|c|c|c|c|c|c|c|c|c|c|c|c|c|}
\hline \multirow[b]{2}{*}{$m_{0}$} & \multirow[b]{2}{*}{$T_{n}$} & \multirow[b]{2}{*}{$\eta$} & \multicolumn{2}{|c|}{ Variation } & \multicolumn{2}{|c|}{$\tau_{\delta_{\gamma}}$} & \multirow[b]{2}{*}{$\mathrm{CAP}_{w}$} & \multirow[b]{2}{*}{$\mathrm{CAP}_{m}$} & \multirow[b]{2}{*}{$m_{0}$} & \multirow[b]{2}{*}{$T_{n}$} & \multirow[b]{2}{*}{$\eta$} & \multicolumn{2}{|c|}{ Variation } & \multicolumn{2}{|c|}{$\tau_{\delta_{\gamma}}$} & \multirow[b]{2}{*}{$\mathrm{CAP}_{w}$} & \multirow[b]{2}{*}{$\mathrm{CAP}_{m}$} \\
\hline & & & $T_{n V}$ & $\eta_{V}$ & $M$ & SD & & & & & & $T_{n V}$ & $\overline{\eta_{V}}$ & $M$ & SD & & \\
\hline 15 & 0.1 & 0.00 & $\mathrm{~N}$ & $\mathrm{~N}$ & 41 & 1 & 0.48 & 0.48 & 20 & 0.3 & 0.01 & $\mathrm{Y}$ & $\mathrm{Y}$ & 41 & 2 & 0.65 & 0.26 \\
\hline 15 & 0.1 & 0.00 & $\mathrm{Y}$ & $\mathrm{N}$ & 41 & 2 & 0.48 & 0.49 & 20 & 0.3 & 0.10 & $\mathrm{~N}$ & $\mathrm{~N}$ & 41 & 1 & 0.82 & 0.11 \\
\hline 15 & 0.1 & 0.01 & $\mathrm{~N}$ & $\mathrm{~N}$ & 42 & 4 & 0.45 & 0.53 & 20 & 0.3 & 0.10 & $\mathrm{~N}$ & Y & 41 & 2 & 0.81 & 0.23 \\
\hline 15 & 0.1 & 0.01 & $\mathrm{~N}$ & $\mathrm{Y}$ & 42 & 2 & 0.50 & 0.51 & 20 & 0.3 & 0.10 & Y & $\mathrm{N}$ & 41 & 2 & 0.89 & 0.17 \\
\hline 15 & 0.1 & 0.01 & Y & $\mathrm{N}$ & 42 & 2 & 0.37 & 0.67 & 20 & 0.3 & 0.10 & $\mathrm{Y}$ & $\mathrm{Y}$ & 41 & 1 & 0.76 & 0.28 \\
\hline 15 & 0.1 & 0.01 & Y & Y & 42 & 3 & 0.27 & 0.75 & & & & & & & & & \\
\hline 15 & 0.1 & 0.10 & $\mathrm{~N}$ & $\mathrm{~N}$ & 228 & 42 & 0.51 & 0.50 & 20 & 0.5 & 0.00 & $\mathrm{~N}$ & $\mathrm{~N}$ & 41 & 1 & 0.05 & 0.91 \\
\hline 15 & 0.1 & 0.10 & $\mathrm{~N}$ & Y & 219 & 43 & 0.45 & 0.57 & 20 & 0.5 & 0.00 & $\mathrm{Y}$ & $\mathrm{N}$ & 41 & 1 & 0.05 & 0.95 \\
\hline 15 & 0.1 & 0.10 & Y & $\mathrm{N}$ & 227 & 42 & 0.34 & 0.66 & 20 & 0.5 & 0.01 & $\mathrm{~N}$ & $\mathrm{~N}$ & 41 & 2 & 0.65 & 0.20 \\
\hline \multirow[t]{2}{*}{15} & 0.1 & 0.10 & Y & $\mathrm{Y}$ & 211 & 42 & 0.34 & 0.70 & 20 & 0.5 & 0.01 & $\mathrm{~N}$ & Y & 41 & 2 & 0.82 & 0.25 \\
\hline & & & & & & & & & 20 & 0.5 & 0.01 & $\mathrm{Y}$ & $\mathrm{N}$ & 41 & 2 & 0.74 & 0.24 \\
\hline 15 & 0.3 & 0.00 & $\mathrm{~N}$ & $\mathrm{~N}$ & 41 & 1 & 0.50 & 0.52 & 20 & 0.5 & 0.01 & Y & Y & 41 & 1 & 0.72 & 0.20 \\
\hline 15 & 0.3 & 0.00 & $\mathrm{Y}$ & $\mathrm{N}$ & 41 & 1 & 0.51 & 0.50 & 20 & 0.5 & 0.10 & $\mathrm{~N}$ & $\mathrm{~N}$ & 41 & 2 & 0.82 & 0.23 \\
\hline 15 & 0.3 & 0.01 & $\mathrm{~N}$ & $\mathrm{~N}$ & 42 & 3 & 0.69 & 0.30 & 20 & 0.5 & 0.10 & $\mathrm{~N}$ & Y & 41 & 2 & 0.62 & 0.22 \\
\hline 15 & 0.3 & 0.01 & $\mathrm{~N}$ & Y & 42 & 3 & 0.65 & 0.38 & 20 & 0.5 & 0.10 & Y & $\mathrm{N}$ & 41 & 1 & 0.86 & 0.24 \\
\hline 15 & 0.3 & 0.01 & Y & $\mathrm{N}$ & 42 & 2 & 0.62 & 0.37 & 20 & 0.5 & 0.10 & Y & Y & 41 & 2 & 0.72 & 0.33 \\
\hline 15 & 0.3 & 0.01 & Y & Y & 43 & 3 & 0.65 & 0.32 & & & & & & & & & \\
\hline 15 & 0.3 & 0.10 & $\mathrm{~N}$ & $\mathrm{~N}$ & 43 & 5 & 0.66 & 0.32 & 25 & 0.1 & 0.00 & $\mathrm{~N}$ & $\mathrm{~N}$ & 50 & 0 & . & . \\
\hline 15 & 0.3 & 0.10 & $\mathrm{~N}$ & $\mathrm{Y}$ & 43 & 4 & 0.59 & 0.41 & 25 & 0.1 & 0.00 & Y & $\mathrm{N}$ & 50 & 0 & . & . \\
\hline 15 & 0.3 & 0.10 & Y & $\mathrm{N}$ & 43 & 3 & 0.73 & 0.27 & 25 & 0.1 & 0.01 & $\mathrm{~N}$ & $\mathrm{~N}$ & 50 & 0 & . & . \\
\hline 15 & 0.3 & 0.10 & Y & Y & 43 & 3 & 0.67 & 0.31 & 25 & 0.1 & 0.01 & $\mathrm{~N}$ & Y & 50 & 0 & . & . \\
\hline & & & & & & & & & 25 & 0.1 & 0.01 & Y & $\mathrm{N}$ & 50 & 0 & . & . \\
\hline 15 & 0.5 & 0.00 & $\mathrm{~N}$ & $\mathrm{~N}$ & 41 & 1 & 0.49 & 0.48 & 25 & 0.1 & 0.01 & Y & Y & 50 & 0 & . & . \\
\hline 15 & 0.5 & 0.00 & Y & $\mathrm{N}$ & 41 & 1 & 0.49 & 0.50 & 25 & 0.1 & 0.10 & $\mathrm{~N}$ & $\mathrm{~N}$ & 50 & 0 & . & . \\
\hline 15 & 0.5 & 0.01 & $\mathrm{~N}$ & $\mathrm{~N}$ & 42 & 2 & 0.60 & 0.42 & 25 & 0.1 & 0.10 & $\mathrm{~N}$ & Y & 50 & 0 & . & . \\
\hline 15 & 0.5 & 0.01 & $\mathrm{~N}$ & Y & 41 & 2 & 0.60 & 0.35 & 25 & 0.1 & 0.10 & Y & $\mathrm{N}$ & 50 & 0 & . & . \\
\hline 15 & 0.5 & 0.01 & Y & $\mathrm{N}$ & 42 & 3 & 0.62 & 0.42 & 25 & 0.1 & 0.10 & Y & Y & 50 & 0 & . & . \\
\hline 15 & 0.5 & 0.01 & $\mathrm{Y}$ & $\mathrm{Y}$ & 42 & 3 & 0.62 & 0.34 & & & & & & & & & \\
\hline 15 & 0.5 & 0.10 & $\mathrm{~N}$ & $\mathrm{~N}$ & 43 & 6 & 0.68 & 0.29 & 25 & 0.3 & 0.00 & $\mathrm{~N}$ & $\mathrm{~N}$ & 50 & 0 & . & . \\
\hline 15 & 0.5 & 0.10 & $\mathrm{~N}$ & Y & 42 & 3 & 0.62 & 0.38 & 25 & 0.3 & 0.00 & Y & $\mathrm{N}$ & 50 & 0 & . & . \\
\hline 15 & 0.5 & 0.10 & Y & $\mathrm{N}$ & 42 & 4 & 0.67 & 0.37 & 25 & 0.3 & 0.01 & $\mathrm{~N}$ & $\mathrm{~N}$ & 50 & 0 & . & . \\
\hline 15 & 0.5 & 0.10 & Y & $\mathrm{Y}$ & 44 & 18 & 0.68 & 0.30 & 25 & 0.3 & 0.01 & $\mathrm{~N}$ & Y & 50 & 0 & . & . \\
\hline & & & & & & & & & 25 & 0.3 & 0.01 & Y & $\mathrm{N}$ & 50 & 0 & . & . \\
\hline 20 & 0.1 & 0.00 & $\mathrm{~N}$ & $\mathrm{~N}$ & 41 & 1 & 0.06 & 0.98 & 25 & 0.3 & 0.01 & Y & Y & 50 & 0 & . & . \\
\hline 20 & 0.1 & 0.00 & $\mathrm{Y}$ & $\mathrm{N}$ & 41 & 2 & 0.09 & 0.87 & 25 & 0.3 & 0.10 & $\mathrm{~N}$ & $\mathrm{~N}$ & 50 & 0 & . & . \\
\hline 20 & 0.1 & 0.01 & $\mathrm{~N}$ & $\mathrm{~N}$ & 41 & 1 & 0.38 & 0.56 & 25 & 0.3 & 0.10 & $\mathrm{~N}$ & Y & 50 & 0 & . & . \\
\hline 20 & 0.1 & 0.01 & $\mathrm{~N}$ & Y & 41 & 1 & 0.39 & 0.63 & 25 & 0.3 & 0.10 & Y & $\mathrm{N}$ & 50 & 0 & . & . \\
\hline 20 & 0.1 & 0.01 & $\mathrm{Y}$ & $\mathrm{N}$ & 41 & 1 & 0.20 & 0.97 & 25 & 0.3 & 0.10 & Y & Y & 50 & 0 & . & . \\
\hline 20 & 0.1 & 0.01 & $\mathrm{Y}$ & Y & 41 & 1 & 0.24 & 0.71 & & & & & & & & & \\
\hline 20 & 0.1 & 0.10 & $\mathrm{~N}$ & $\mathrm{~N}$ & 41 & 1 & 0.41 & 0.60 & 25 & 0.5 & 0.00 & $\mathrm{~N}$ & $\mathrm{~N}$ & 50 & 0 & 0.00 & . \\
\hline 20 & 0.1 & 0.10 & $\mathrm{~N}$ & Y & 41 & 1 & 0.33 & 0.57 & 25 & 0.5 & 0.00 & Y & $\mathrm{N}$ & 50 & 0 & . & . \\
\hline 20 & 0.1 & 0.10 & Y & $\mathrm{N}$ & 41 & 1 & 0.28 & 0.72 & 25 & 0.5 & 0.01 & $\mathrm{~N}$ & $\mathrm{~N}$ & 50 & 0 & . & . \\
\hline 20 & 0.1 & 0.10 & Y & Y & 41 & 2 & 0.22 & 0.81 & 25 & 0.5 & 0.01 & $\mathrm{~N}$ & Y & 50 & 0 & . & . \\
\hline & & & & & & & & & 25 & 0.5 & 0.01 & Y & $\mathrm{N}$ & 50 & 0 & . & . \\
\hline 20 & 0.3 & 0.00 & $\mathrm{~N}$ & $\mathrm{~N}$ & 41 & 1 & 0.03 & 0.84 & 25 & 0.5 & 0.01 & Y & Y & 50 & 0 & . & . \\
\hline 20 & 0.3 & 0.00 & $\mathrm{Y}$ & $\mathrm{N}$ & 41 & 1 & 0.04 & 0.85 & 25 & 0.5 & 0.10 & $\mathrm{~N}$ & $\mathrm{~N}$ & 50 & 0 & . & . \\
\hline 20 & 0.3 & 0.01 & $\mathrm{~N}$ & $\mathrm{~N}$ & 41 & 2 & 0.75 & 0.28 & 25 & 0.5 & 0.10 & $\mathrm{~N}$ & Y & 50 & 0 & 1.00 & . \\
\hline 20 & 0.3 & 0.01 & $\mathrm{~N}$ & Y & 41 & 1 & 0.78 & 0.14 & 25 & 0.5 & 0.10 & Y & $\mathrm{N}$ & 50 & 0 & . & . \\
\hline 20 & 0.3 & 0.01 & Y & $\mathrm{N}$ & 41 & 1 & 0.72 & 0.26 & 25 & 0.5 & 0.10 & Y & Y & 50 & 0 & 1.00 & 0.00 \\
\hline
\end{tabular}

$T_{n V}$ and $\eta_{V}$ indicate whether $T_{n}$ and $\eta$ vary or not. 
terms of stopping time. The coverage probabilities of treatment differences cannot be computed because the covariate is ignored. Instead, coverages of intercept differences are given in Table 4 and are mostly larger than the nominal level 0.95 since there are less additional samples collected for larger $m_{0}$.

Correct allocation probabilities (CAP) for $m_{0}=25$ are not computed since there are no additional samples collected after initial samples. CAPs for $m_{0}=20$ are not reliable since only one or two additional samples were collected after the initial stage. CAPs for $m_{0}=15$ are computed with the 11-14 additional samples and similar observations with the ones when the covariate is considered are found but with smaller CAPs. This is due to asymmetric distribution of KRAS population on both sides of intersection of two logistic curves for treatment effects not due to covariate consideration.

These findings also confirm that response-adaptive allocation ignoring significantly interacting covariate with treatment groups does not play an ethical role by failing to skew the allocation for the better treatment group.

\section{Conclusion}

When significant interaction between treatment and covariates is ignored, study stops earlier than expected once a few additional samples are collected. This makes it difficult to try skewed allocation for better treatment and results in wrong treatment allocation. Throughout the paper, we have demonstrated the importance of considering covariates that interact with the treatment allocation in a RA design. For a real-world practice, it is recommended to investigate whether there are some possible covariates interacting with the treatment for a RA design.

\section{Acknowledgments}

This study was financially supported by Chonnam National University, 2014.

\section{References}

Bandyopadhyay U, Biswas A, and Bhattacharya R (2007). A covariate adjusted two-stage allocation design for binary responses in randomized clinical trials, Statistics in Medicine, 26, 4386-4399.

Chang YI and Park E (2013). Sequential estimation for covariate-adjusted response-adaptive designs, Journal of the Korean Statistical Society, 42, 105-116.

Hu F and Rosenberger WF (2006). The Theory of the Response-Adaptive Randomization in Clinical Trials, Wiley Inter Science, London.

McCullagh P and Nelder JA (1989). Generalized Linear Models (2nd ed), Chapman and Hall, London, UK.

Van Cutsem E, Köhne CH, Hitre E, Zaluski J, Chang Chien CR, Makhson A, et al. (2009). Cetuximab and chemotherapy as initial treatment for metastatic colorectal cancer, New England Journal of Medicine, 360, 1408-1417.

Zelen M and Wei LJ (1995). Foreword. In N Flournoy and WF Rosenberger (Eds), Adaptive Designs, Institute of Mathematical Statistics, Hayward, CA.

Zhang LX, Hu F, Cheung SH, and Chan WS (2007). Asymptotic properties of covariate-adjusted response-adaptive designs, Annals of Statistics, 35, 1166-1182. 